\title{
Electrochemical Corrosion Properties of AZ91 Mg Alloy via Plasma Electrolytic Oxidation and Subsequent Annealing
}

\author{
Young Gun $\mathrm{Ko}^{1}$, Kang Min Lee ${ }^{2}$ and Dong Hyuk Shin ${ }^{2, *}$ \\ ${ }^{1}$ School of Materials Science and Engineering, Yeungnam University, Gyeongsan 712-749, Korea \\ ${ }^{2}$ Department of Metallurgy and Materials Engineering, Hanyang University, Ansan 425-791, Korea
}

\begin{abstract}
The paper demonstrated the electrochemical corrosion properties of the oxide film of AZ91 Mg alloy subjected to plasma electrolytic oxidation (PEO) coating in an electrolyte containing zirconia and additional heat treatment. Surface observation revealed that a number of zirconia particles were successfully incorporated and were also uniformly distributed throughout the oxide film. After subsequent heat treatment, the relative fraction of $\mathrm{Mg}(\mathrm{OH})_{2}$ decreased whilst the fraction of $\mathrm{MgO}$ increased in the oxide film due to the dehydration reaction at $423 \mathrm{~K}$. From the results of electrochemical impedance spectroscopy, the excellent corrosion resistance of AZ91 Mg alloy could be achieved via PEO coating together with annealing treatment. Electrochemical response underlying corrosion response of the present alloy was discussed in relation to equivalent circuit model. [doi:10.2320/matertrans.M2011112]
\end{abstract}

(Received April 13, 2011; Accepted May 23, 2011; Published July 6, 2011)

Keywords: AZ91 magnesium alloy, plasma electrolytic oxidation, annealing, zirconia, equivalent circuit model

\section{Introduction}

With the rapid growth in electronic industries over the past decade, much attention has focused on the development of $\mathrm{Mg}$ alloy, which were known as one of the good candidates having light weight, high specific strength, etc. ${ }^{1-3)}$ In spite of these inherent properties, the active oxidation rate of $\mathrm{Mg}$ alloy limited their commercial applications in various fields where the corrosion-protection properties were required. $\left.{ }^{4,5}\right)$ To protect $\mathrm{Mg}$ alloy from oxidation, several surface treatment methods such as electroplating, anodizing and plasma electrolytic oxidation (PEO) coating have been developed. $^{6-8)}$ Among these techniques, PEO coating would be one of the most attractive surface treatment methods suitable for $\mathrm{Mg}$ alloy by introducing a thin oxide film to $\mathrm{Mg}$ alloy within a plasma state which was generated by an extremely high anodic potential in wet conditions. ${ }^{9-12)}$ The surface morphologies formed by PEO coating would depend highly on electrolyte conditions including composition, concentration, and chemical additive. It is important to determine an appropriate electrolyte in order to improve the corrosion resistance. Thus, Thomson et al. ${ }^{13,14)}$ investigated the influence of zirconia incorporation on the corrosion resistance of valve materials. Indeed, Hwang et al. ${ }^{15)}$ reported that the polarization resistance would be enhanced by subsequent heat treatment since the amount of $\mathrm{MgO}$ increased due to the dehydration reaction during annealing. However, few researches have explored how the corrosion resistance of $\mathrm{Mg}$ alloy would be altered if two beneficial effects coming from both the addition of zirconia to the electrolyte and the subsequent annealing would be combined. Therefore, the main purpose of the present study is to investigate the influences of zirconia incorporation in the electrolyte and annealing treatment on the surface micro-morphology, chemical composition, and corrosion response of the PEOtreated $\mathrm{Mg}$ alloy.
Table 1 Compositions of the electrolytes used for the present PEO coating process.

\begin{tabular}{ccccc}
\hline & $\begin{array}{c}\text { potassium } \\
\text { hydroxide } \\
(\mathrm{mol} / \mathrm{L})\end{array}$ & $\begin{array}{c}\text { potassium } \\
\text { fluoride } \\
(\mathrm{mol} / \mathrm{L})\end{array}$ & $\begin{array}{c}\text { potassium } \\
\text { pyrophosphate } \\
(\mathrm{mol} / \mathrm{L})\end{array}$ & $\begin{array}{c}\text { zirconia } \\
(\mathrm{mol} / \mathrm{L})\end{array}$ \\
\hline without zirconia & 0.089 & 0.052 & 0.009 & - \\
\hline with zirconia & 0.089 & 0.052 & 0.009 & 0.073 \\
\hline
\end{tabular}

\section{Experimental Procedures}

A commercial AZ91 Mg alloy plate provided by POSCO was cut into $30 \times 50 \times 2 \mathrm{~mm}$ specimens, which were polished with emery papers and rinsed with distilled water. Then, specimens were ultrasonically cleaned in ethanol and dried with warm air. PEO coating was performed on the specimen for $430 \mathrm{~s}$ with a $20 \mathrm{~kW}$ power supply using stainless steel as the counter electrode. Stirring and cooling system were installed to maintain the electrolyte temperature. The applied current density was fixed at $50 \mathrm{~mA} / \mathrm{cm}^{2}$. Table 1 lists the chemical compositions of the electrolytes used for this study. After PEO coating, the specimen was subsequently annealed at $423 \mathrm{~K}$.

The surface morphologies of the oxide films were observed utilizing a scanning electron microscope (SEM). Additional particles in oxide films were analyzed based on energy dispersive spectroscopy (EDS). For chemical analysis, X-ray photoelectron spectroscopy (XPS) was used with a monochromatic Al $K \alpha$ source. Also, the corrosion characteristics of AZ91 Mg alloy was evaluated using electrochemical impedance spectroscopy (EIS) consisting of three electrodes: AZ91 Mg alloy specimen as a working electrode, a platinum mesh as a counter electrode, and an $\mathrm{Ag} / \mathrm{AgCl}$ electrode as a reference electrode. 
Table 2 Responding voltages of AZ91 Mg alloy specimens during PEO coating.

\begin{tabular}{cccc}
\hline & $\begin{array}{c}\text { breakdown voltage } \\
(\mathrm{V})\end{array}$ & $\begin{array}{c}\text { critical voltage } \\
(\mathrm{V})\end{array}$ & $\begin{array}{c}\text { final voltage } \\
(\mathrm{V})\end{array}$ \\
\hline without zirconia & 176 & 378 & 390 \\
\hline with zirconia & 177 & 384 & 398 \\
\hline
\end{tabular}

(a)

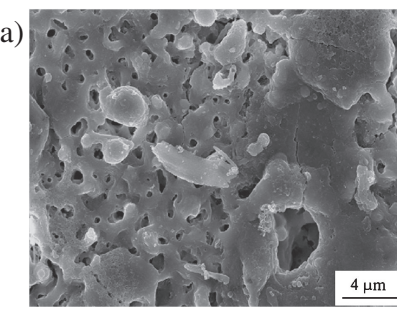

(c)
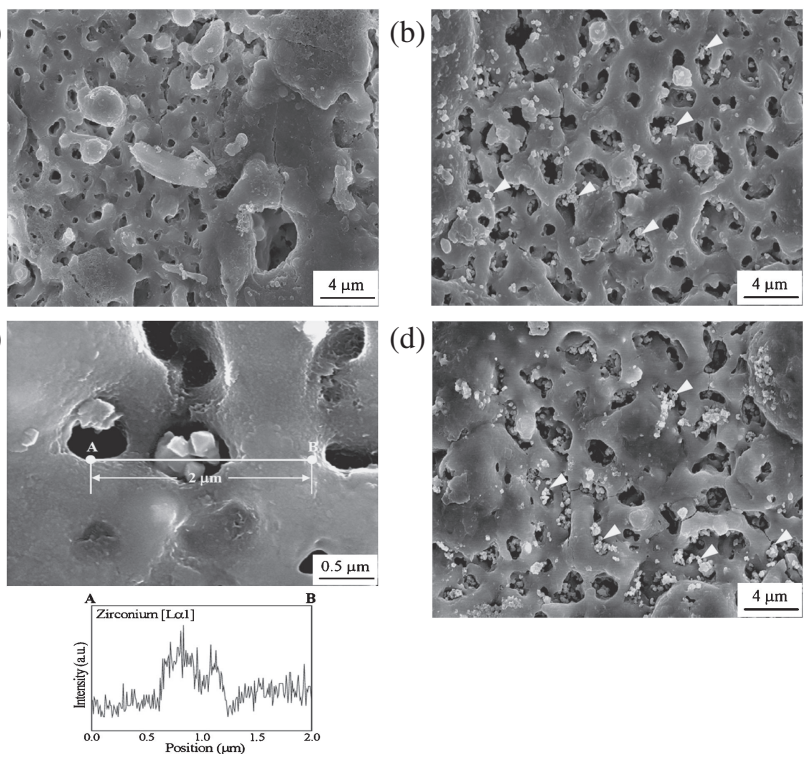

(d)

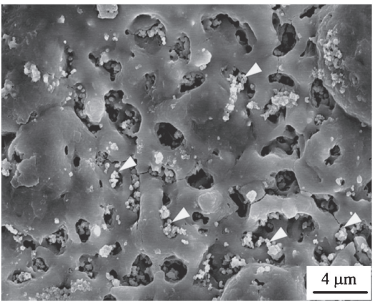

Fig. 1 SEM images showing the surface morphologies of the PEO-coated AZ91 Mg alloy specimens: (a) without zirconia, (b) with zirconia, (c) EDS profile with zirconia, and (d) with zirconia followed by annealing treatment. The arrows in Figs. (b) and (d) indicate the zirconia particles.

\section{Results and Discussion}

The coating time and voltage values of AZ91 Mg alloy processed by PEO coating in two electrolytes without and with zirconia powders are tabulated in Table 2. Irrespective of two electrolytes used in this study, the voltage values during PEO coating increased steeply with a small difference between two conditions at the onset of the breakdown point where thin oxide films readily started to form on the surface of AZ91 Mg alloy. This fact indicated that the effect of zirconia addition to the electrolyte on the oxidation potential was likely to be less significant at the initial stage of PEO coating.

Figure 1 shows the surface morphologies of the PEOcoated $\mathrm{Mg}$ specimens under three different conditions: PEO coatings without and with zirconia and PEO coating with zirconia followed by subsequent annealing. The SEM micrographs of the oxide films in AZ91 Mg alloy coated in the electrolytes without and with zirconia powders are represented in Fig. 1(a) and (b), respectively. In general, when a strong dielectric voltage exceeded the breakdown voltage, plasma bubbles and melting oxides can be thrown out through the channel, causing the micro-channels and pores during PEO coating. ${ }^{8,16)}$ Thus, the surfaces of both specimens possessed a number of pores with an average size of $\sim 1 \mu \mathrm{m}$. It is also found that the surface structure of the specimen with zirconia differed from that without zirconia. According to the elemental analysis using EDS line scanning (Fig. 1(c)), zirconia particles were detected mainly in the vicinity of micro-pores. This finding was attributed to the electrophoretic interaction between zirconia and $\mathrm{Mg}$ substrate and the mechanical mixing in molten spots of magnesium oxide during plasma coating accompanying an electrochemical high energy state. Figure 1(d) exhibited the surface morphology of the oxide film of AZ91 Mg alloy specimens coated through PEO coating in the electrolyte containing the zirconia powder followed by annealing treatment at $423 \mathrm{~K}$. According to the earlier work reported by Hwang et al. ${ }^{15)}$ the relative ratio of $\mathrm{MgO} / \mathrm{Mg}(\mathrm{OH})_{2}$ in the oxide films was affected by subsequent annealing due to the dehydration reaction of $\mathrm{Mg}(\mathrm{OH})_{2}$ to form $\mathrm{MgO}$ with increasing annealing time. An annealing temperature of $423 \mathrm{~K}$ was reported to be desirable for increasing the amount of passive $\mathrm{MgO}$ compound without inducing noticeable cracks on oxide surface. Despite the annealing treatment at $423 \mathrm{~K}$, however, the average size and distribution of micro-pores remained unchanged, implying the fact that the influence of annealing treatment on the surface pore structure appeared to be insignificant. Instead, annealing treatment led to a change in fraction of compounds present in the oxide film.

Figure 2 displays the XPS spectra ( $\mathrm{Mg} \mathrm{2p} \mathrm{3/2)} \mathrm{of} \mathrm{the}$ PEO-coated AZ91 Mg alloy specimens under three different conditions in order to observe which compounds were present. The binding energy at $49.4 \mathrm{eV}$ indicated the existence of $\mathrm{Mg}(\mathrm{OH})_{2}$ whereas the binding energy at $50.3 \mathrm{eV}$ was associated with the formation of $\mathrm{MgO}$. Due to the qualitative nature of XPS results, it is no meaning to compare the peak intensity directly from each data, so that the comparison of relative intensity in XPS spectra was used in this study. Since zirconia did not react actively with the electrolyte during coating, the relative ratio of $\mathrm{MgO}$ / $\mathrm{Mg}(\mathrm{OH})_{2}$ in the specimen without zirconia particles was same as that with them. It is interesting to note that the peak intensity of $\mathrm{MgO}$ in the specimen with annealing was relatively higher than that without annealing. Such comparative difference in peak intensity found between Fig. 2(b) and (c) suggested that the relative amount of $\mathrm{MgO}$ compound in the oxide films increased and the amount of $\mathrm{Mg}(\mathrm{OH})_{2}$ decreased when the specimen was additional annealed after PEO coating. Sharma et al. ${ }^{17)}$ demonstrated based on thermal analysis that the dehydration reaction was endothermic and would occur at a temperature of $\sim 410 \mathrm{~K}$ at which $\mathrm{Mg}(\mathrm{OH})_{2}$ in the oxide film was divided into $\mathrm{MgO}$ and $\mathrm{H}_{2} \mathrm{O} .{ }^{18)}$ Thus, the present change in the relative ratio of $\mathrm{MgO} / \mathrm{Mg}(\mathrm{OH})_{2}$ was mainly due to the dehydration of $\mathrm{Mg}(\mathrm{OH})_{2}$ to form $\mathrm{MgO}$. Interestingly, $\mathrm{MgO}$ compound was less active than $\mathrm{Mg}(\mathrm{OH})_{2}$ in terms of corrosion potential. ${ }^{4,19,20)}$ Accordingly, annealing treatment would be useful for enhancing corrosion resistance of AZ91 Mg alloy without changing the pore size and distribution.

The corrosion characteristics of three PEO-coated AZ91 $\mathrm{Mg}$ alloy specimens were evaluated by EIS tests in a 3.5 mass $\% \mathrm{NaCl}$ solution similar to seawater, and corrosion behavior was also discussed within the framework of the equivalent circuit model. As shown in Fig. 3, the equivalent circuit model was employed to simulate the experimental data and then extract several parameters characterizing the 

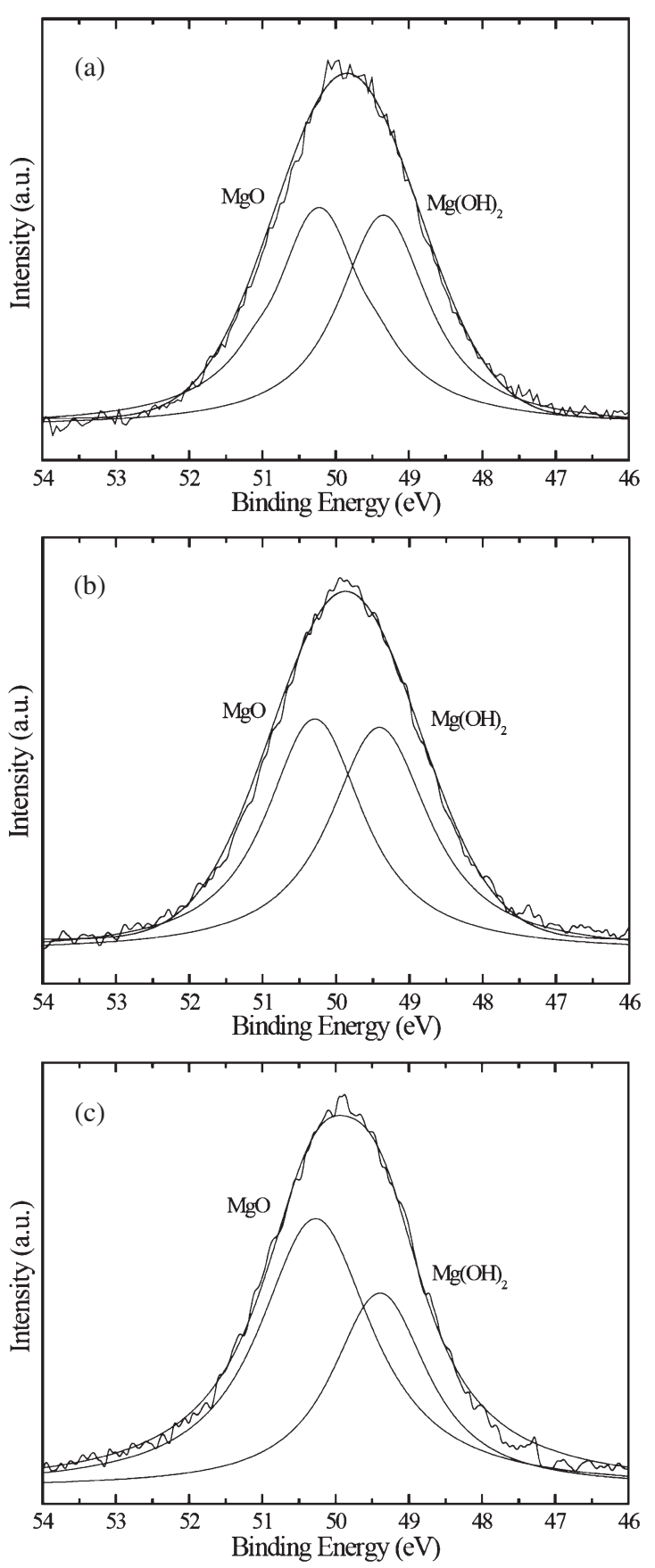

Fig. 2 XPS analyses of the PEO-coated AZ91 Mg alloy specimens: (a) without zirconia, (b) with zirconia, and (c) with zirconia followed by annealing treatment.

corrosion characteristics. Due to the complicated nature of electrochemical activities, several electrode processes might be placed either in series or in parallel with each other. However, since the impedance system between reference and working electrodes consisted of three different parts such as electrolyte, external and internal oxide films, two constant phase element (CPE) components were in series with the electrolyte resistance $\left(R_{\mathrm{S}}\right)$. The resistances associated with the external $\left(R_{\mathrm{e}}\right)$ and the internal $\left(R_{\mathrm{i}}\right)$ films were connected in parallel with their CPE. ${ }^{21-23)}$

Figure 4 shows that an excellent fit was made between the experimental data and iterated results based on the equivalent circuit model. The corresponding values of the equivalent

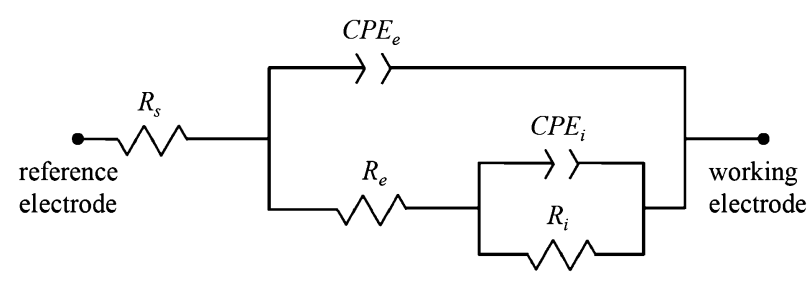

Fig. 3 Equivalent circuit model used for analyzing impedance data of three different specimens of the PEO-coated AZ91 Mg alloy.

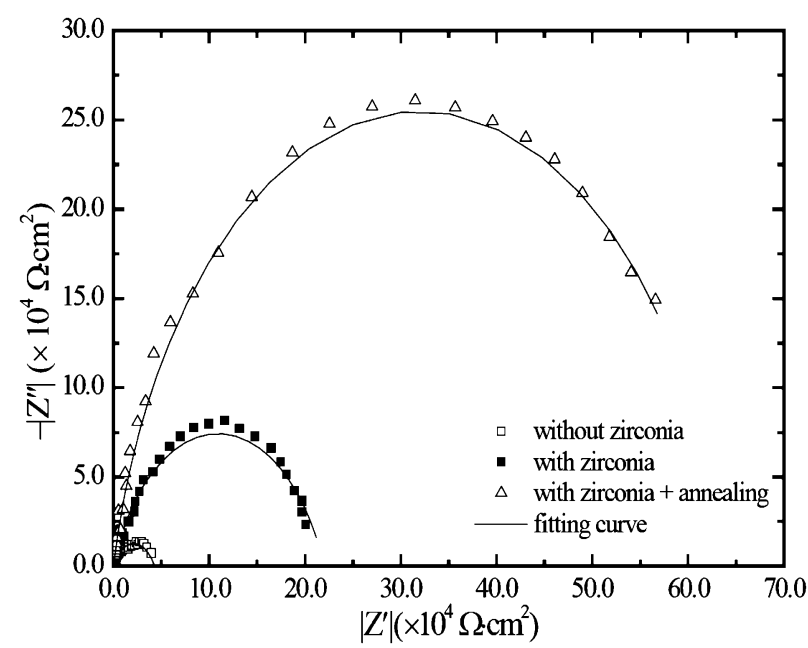

Fig. 4 Impedance test data of the PEO-coated AZ91 Mg alloy specimens and the fitting results of their electrochemical plots based on the equivalent circuit model.

Table 3 Fitting results of the PEO-coated AZ91 Mg alloy specimens based on the equivalent circuit model. The impedances of two constant phase elements are defined by a dimensionless $n$ parameter. Subscripts of e and i stand for the external and the internal oxide films, respectively.

\begin{tabular}{cccccc}
\hline & $\begin{array}{c}R_{\mathrm{S}} \\
\left(\Omega \cdot \mathrm{cm}^{2}\right)\end{array}$ & $\begin{array}{c}R_{\mathrm{e}} \\
\left(\Omega \cdot \mathrm{cm}^{2}\right)\end{array}$ & $\begin{array}{c}R_{\mathrm{i}} \\
\left(\Omega \cdot \mathrm{cm}^{2}\right)\end{array}$ & $C P E_{\mathrm{e}}-n$ & $C P E_{\mathrm{i}}-n$ \\
\hline without zirconia & 21.3 & $1.03 \times 10^{3}$ & $8.87 \times 10^{4}$ & 0.924 & 0.459 \\
\hline with zirconia & 20.1 & $1.32 \times 10^{4}$ & $2.17 \times 10^{5}$ & 0.824 & 0.723 \\
\hline $\begin{array}{l}\text { with zirconia } \\
+ \text { annealing }\end{array}$ & 20.8 & $1.98 \times 10^{5}$ & $6.39 \times 10^{5}$ & 0.804 & 0.950 \\
\hline
\end{tabular}

elements are listed in Table 3. Comparing earlier work on the plasma-coated $\mathrm{Mg}$ alloy specimens to the present work, it seemed that the present data were well interpreted. ${ }^{24-27)}$

According to Table 3 , the values of $R_{\mathrm{e}}$ and $R_{\mathrm{i}}$ would tend to be increased in the order of the specimens coated in the electrolytes without zirconia, with zirconia, and the specimen coated with zirconia followed by annealing. This indicated that the capabilities of the present specimens to overcome oxidation were enhanced as these values increased. The presence of zirconia particles in the electrolyte played an important role in filling the pores during coating as shown in Figs. 1(b)-(d). This contributed to a better corrosion resistance by decreasing contact area between the external corrosive medium and the substrate. The $R_{\mathrm{e}}$ value of the specimen via PEO coating with zirconia and subsequent annealing was measured to be $1.98 \times 10^{5} \Omega \cdot \mathrm{cm}^{2}$, which was 
one-order higher than that with zirconia $\left(1.32 \times 10^{4} \Omega \cdot \mathrm{cm}^{2}\right)$ as well as two-order higher than without zirconia $(1.03 \times$ $\left.10^{3} \Omega \cdot \mathrm{cm}^{2}\right)$. This indicated that the best corrosion performance was attained when the combination of zirconia and annealing could be used. The change from semi-passive $\mathrm{Mg}(\mathrm{OH})_{2}$ to passive $\mathrm{MgO}$ in the oxide film was expected to play a role in preventing the penetration of the corrosion ions through the oxide film. It is concluded that the combination of zirconia incorporation and transformation of $\mathrm{Mg}(\mathrm{OH})_{2}$ to induce $\mathrm{MgO}$ by subsequent annealing was desirable for enhancing the anti-corrosion properties of AZ91 Mg alloy.

\section{Conclusions}

The influences of zirconia powder and annealing treatment on morphological changes and corrosion characteristics of the PEO-coated AZ91 Mg alloy were studied. A number of zirconia particles were successfully incorporated into this oxide film during PEO coating. They existed uniformly, which might enhance the corrosion resistance. According to EIS analysis based on equivalent circuit model, the annealing treatment was also beneficial for the corrosion resistance by allowing $\mathrm{MgO}$ compound in the oxide film to increase due to the dehydration reaction. Thus, the zirconia incorporation together with the annealing treatment in this study could be combined for achieving good electrochemical properties of AZ91 Mg alloy.

\section{Acknowledgements}

This work was supported by the National Research Foundation of Korea (2010-0000812).

\section{REFERENCES}

1) R. Nandan, T. DebRoy and H. K. D. H. Bhadeshia: Prog. Mater. Sci. 53 (2008) 980-1023.

2) B. L. Mordike and T. Ebert: Mater. Sci. Eng. A 302 (2001) 37-45.

3) J. E. Gray and B. Luan: J. Alloy. Compd. 336 (2002) 88-113.
4) G. L. Song and A. Atrens: Adv. Eng. Mater. 1 (1999) 11-33.

5) N. J. Park, J. H. Hwang and J. S. Roh: J. Kor. Inst. Met. Mater. 47 (2009) 1-6.

6) Y. W. Song, D. Y. Shan and E. H. Han: Electrochim. Acta 53 (2008) 2135-2143.

7) O. Khaselev, D. Weiss and J. Yahalom: J. Electrochem. Soc. 146 (1999) 1757-1761.

8) A. L. Yerokhin, X. Nie, A. Leyland, A. Matthews and S. J. Dowey: Surf. Coat. Technol. 122 (1999) 73-93.

9) J. A. Curran and T. W. Clyne: Acta Mater. 54 (2006) 1985-1993.

10) P. B. Srinivasan, C. Blawert, W. Dietzel and K. U. Kainer: Scr. Mater. 59 (2008) 43-46.

11) Y. Han, Y. Yan and C. Lu: Thin Solid Films 517 (2009) 1577-1581.

12) Y. G. Ko, K. M. Lee, K. R. Shin and D. H. Shin: Kor. J. Met. Mater. 48 (2010) 724-729.

13) R. Arrabal, E. Matykina, P. Skeldon and G. E. Thompson: J. Mater. Sci. 43 (2008) 1532-1538.

14) E. Matykina, R. Arrabal, P. Skeldon and G. E. Thompson: Electrochim. Acta 54 (2009) 6767-6778.

15) D. Y. Hwang, Y. G. Ko, Y. M. Kim, B. Yoo and D. H. Shin: Mater. Trans. 51 (2010) 408-412.

16) A. L. Yerokhin, L. O. Snizhko, N. L. Gurevina, A. Leyland, A. Pilkington and A. Matthews: J. Phys. D: Appl. Phys. 36 (2003) 2110 2120 .

17) A. K. Sharma, R. U. Rani and M. Mayanna: Thermochim. Acta 376 (2001) 67-75.

18) Y. Zhang, C. Yan, F. Wang and W. Li: Corros. Sci. 47 (2005) 28162831.

19) C. F. Li, W. H. Ho and S. K. Yen: J. Electrochem. Soc. 156 (2009) E29-E34.

20) C. F. Li, M. J. Wang, W. H. Ho, H. N. Li and S. K. Yen: J. Electrochem. Soc. 158 (2011) C11-C16.

21) K. M. Lee, I. J. Hwang, T. S. Kim, B. Yoo and D. H. Shin: J. Alloy. Compd. 504S (2010) S328-S331.

22) E. V. Parfenov, A. L. Yerokhin and A. Matthews: Thin Solid Films 516 (2007) 428-432.

23) H. Duan, C. Yan and F. Wang: Electrochim. Acta 52 (2007) 37853798.

24) A. Ghasemi, V. S. Raja, C. Blawert, W. Dietzel and K. U. Kainer: Surf. Coat. Technol. 204 (2010) 1469-1478.

25) H. Duan, K. Du, C. Yan and F. Wang: Electrochim. Acta 51 (2006) 2898-2908.

26) Y. W. Song, D. Y. Shan and E. H. Han: Mater. Corros. 58 (2007) 506510.

27) S. Mathieu, C. Rapin, J. Hazan and P. Steinmetz: Corros. Sci. 44 (2002) 2737-2756. 